\title{
Population Estimate for the Bluenose-East Caribou Herd Using Post-Calving Photography
}

\author{
BRENT R. PATTERSON, ${ }^{1}$ BENJAMIN T. OLSEN ${ }^{2}$ and DAMIEN O. JOLY ${ }^{3}$
}

(Received 11 June 2002; accepted in revised form 23 July 2003)

\begin{abstract}
Genetic and spatial analyses suggest that what was previously described as the Bluenose herd of barren-ground caribou (Rangifer tarandus groenlandicus) comprises three separate populations. Of these, the Bluenose-East caribou herd $(\mathrm{BECH})$ has received little coverage in past surveys. Existing estimates of abundance suggested that current harvest rates of Bluenose-East caribou ( $\sim 5000$ animals/year) might be excessive. We used post-calving photography in June-July 2000 to estimate the size of the BECH. A maximum of 33 radio-collared caribou were available for location in June 2000 . We located 30 of these caribou and photographed distinct groups containing 23 collared individuals. Excluding caribou assumed to belong to the neighboring Bluenose-West herd, we photographed a minimum of 84412 adult and 4193 calf caribou. Using a simple markrecapture model to account for caribou associated with collared individuals not photographed, we calculated an estimate of $104000 \pm 22100$ (95\% CI 84 412-126 100) non-calf caribou. A recently published stochastic model produced a considerably higher and more variable estimate of 208700 (95\% CI 112 600-474 700). In March 2001, we deployed seven more radio collars in anticipation of repeating the census in 2001 , but poor weather conditions precluded the formation of large aggregations. Present densities of Bluenose-East caribou seem high, and we recommend regular monitoring of body condition to assess the potential for a forage-induced population crash.
\end{abstract}

Key words: demography, Northwest Territories, Nunavut, population estimation, population size, radio telemetry, Rangifer tarandus

RÉSUMÉ. Des analyses génétiques et spatiales suggèrent que ce que l'on a décrit précédemment comme le troupeau de caribous des toundras Bluenose (Rangifer tarandus groenlandicus) est en fait composé de trois populations distinctes. De ces trois hardes, le troupeau de caribous Bluenose de l'Est (TCBE) n'a pas reçu beaucoup d'attention au cours des relevés antérieurs. Les estimations d'abondance qui existent ont suggéré que le taux de prélèvement actuel de ce caribou ( 5000 animaux/an) pourrait être excessif. On a eu recours à des clichés pris immédiatement après la mise bas en juin-juillet 2000 pour évaluer la taille du TCBE. En juin 2000, un maximum de 33 caribous munis de colliers émetteurs étaient disponibles pour la localisation. On en a repéré 30 et on a photographié des groupes distincts contenant 23 individus équipés de colliers émetteurs. Si l'on exclut les caribous qui feraient partie de la harde voisine Bluenose de l'Ouest, on a photographié un minimum de 84412 adultes et 4193 veaux. En utilisant un simple modèle de marquage-recapture pour tenir compte des caribous reliés aux individus munis de colliers émetteurs non photographiés, on en arrive à une estimation du nombre de caribous excluant les veaux de $104 \quad 000 \pm 22 \quad 100$ (intervalle de confiance de $95 \%$ : 84 412-126 000). Un modèle probabiliste publié récemment a donné une estimation nettement plus élevée et plus variable de 208700 (intervalle de confiance de $95 \%$ : 112 600-474 700). En mars 2001, on a eu recours à sept colliers émetteurs supplémentaires en prévision d'une reprise du recensement en 2001, mais le mauvais temps a empêché la formation de grands regroupements. Les densités actuelles du caribou Bluenose de l'Est semblent élevées, et on recommande une surveillance continue de l'état corporel afin d'évaluer le potentiel d'un effondrement de la population dû à un manque de fourrage.

Mots clés: démographie, Territoires du Nord-Ouest, Nunavut, estimation de la population, taille de la population, radiotélémesure, Rangifer tarandus

Traduit pour la revue Arctic par Nésida Loyer.

\footnotetext{
${ }^{1}$ Government of Nunavut, Department of Sustainable Development, Box 316, Kugluktuk, Nunavut X0B 0E0, Canada; present address: Ontario Ministry of Natural Resources, Wildlife Research and Development Section, 300 Water Street, 3rd Floor North, Peterborough, Ontario K9J 8M5, Canada; brent.patterson@mnr.gov.on.ca

${ }^{2}$ Sahtu Renewable Resources Board, Box 134, Tulita, Northwest Territories X0E 0K0, Canada

${ }^{3}$ Wildlife Ecology Department, University of Wisconsin-Madison, 218 Russell Labs, 1630 Linden Drive, Madison, Wisconsin 53706, U.S.A.

(C) The Arctic Institute of North America
} 


\section{INTRODUCTION}

Banfield (1954) described two distinct herds of barrenground caribou (Rangifer tarandus groenlandicus) extending from the Arctic coast south to Great Bear Lake, and east from the Mackenzie Delta to the Coppermine River (Fig. 1). Thomas (1969) considered these caribou to be from one herd, for which he coined the term "Bluenose herd." Although caribou in this area have been managed as a single population since the 1960 s, recent genetic analyses suggest that what is presently described as the Bluenose herd comprises three distinct populations (J.A. Nagy et al., unpubl. data). These genetic data and analysis of location data obtained from radio-collared caribou suggest a discontinuous distribution of barren-ground caribou to the west and to the east of Bluenose Lake $\left(68^{\circ} 20^{\prime} \mathrm{N}, 119^{\circ} 45^{\prime} \mathrm{W}\right)$ (J.A. Nagy et al., 1999; unpubl. data). Caribou that calve on either side of Bluenose Lake shall hereafter be referred to as the Bluenose-East and Bluenose-West caribou herds, respectively (J.A. Nagy et al., unpubl. data). The BluenoseEast caribou herd $(\mathrm{BECH})$ has received little reported coverage in past surveys, which targeted primarily the range of the Bluenose-West herd. Thus, the size and distribution of the BECH has never been adequately defined (Nagy et al., 1999). Population estimation and delineation of the range of the BECH have direct implications for the management of this newly defined herd, and this information is a prerequisite for monitoring population trends and establishing sustainable harvest levels.

On the basis of limited coverage during a 1992 postcalving photo census, the $\mathrm{BECH}$ was estimated at only 13600-19000 animals (Nagy et al., 1999). Although precise data are unavailable, reports from hunters in Kugluktuk suggest a harvest of $\sim 2000$ Bluenose-East caribou per year in Nunavut. Additionally, harvest studies suggest that $2500-3000$ barren-ground caribou are harvested each year from the Bluenose-East and BluenoseWest herds in the Sahtu region of the Northwest Territories (NWT) (Janet Bayha, Sahtu Renewable Resources Board, pers. comm. 2003). If the 1992 estimate of the size of the eastern herd is even remotely accurate, present harvest rates of Bluenose-East caribou ( $24 \%-37 \%$, from figures presented above) are excessive. Clearly it is important to provide a more reliable estimate of the size and distribution of the newly defined BECH.

Post-calving photo surveys of the former Bluenose caribou herd (based on complete counts of aggregations associated with radio-collared caribou) were tested during 1986 and 1987 (McLean and Russell, 1992) and appear to provide more accurate estimates than traditional observerbased aerial surveys (McLean and Russell, 1992). Given the dispersion and annual variation in the calving ground locations of Bluenose caribou (Nagy et al., 1999), this method may be preferred over surveys of caribou on the calving grounds (see also Valkenburg et al., 1985; Couturier et al., 1996; Rivest et al., 1998). Furthermore, a minimum estimate provides a firm number for assessing potential effects of estimated harvest levels. Herein we report the results of a post-calving photo census conducted in July 2000 to estimate the size of the BECH. We attempted to repeat the census in 2001, but weather conditions precluded the formation of large caribou aggregations suitable for photography.

\section{METHODS}

\section{Study Area}

The post-calving range of the $\mathrm{BECH}$ is within $100 \mathrm{~km}$ of the coast of the Arctic Ocean and extends from Bluenose Lake $\left(68^{\circ} 20^{\prime} \mathrm{N}, 119^{\circ} 45^{\prime} \mathrm{W}\right)$ to areas just east of the Coppermine River (Fig. 1). This area is part of a welldrained peneplain with lakes in the hollows and scattered depressions. Rock hills, outcrops, and glaciofluvial features such as eskers, drumlins, and raised beaches are often the only major relief features of this region. Ground cover is predominantly lush willow (Salix sp.) and sedge (Carex sp.) vegetation (Jacobsen, 1979). This area is characterized by short, cool summers (mean temperature: $10^{\circ} \mathrm{C}$ ) and long, cold winters, when temperatures often fall below $-30^{\circ} \mathrm{C}$. The western edge of the post-calving range of the Bathurst caribou herd begins about $100 \mathrm{~km}$ east of the present study area (Gunn and Dragon, 2000).

\section{VHF Radio Collar Deployment}

During 9-15 September 1999, we used a handheld net gun fired from a Bell 206B helicopter to capture 34 adult female caribou (Fig. 2). We collected genetic samples and feces and then fit each cow with a VHF radio collar. We used a fixed-wing aircraft (Aviat Husky), guided by current locations of caribou previously fit with satellite collars (J.A. Nagy et al., unpubl. data) to define the distribution of Bluenose-East caribou before deploying the VHF radio collars. We then attempted to deploy the radio collars evenly across the geographic range of the $\mathrm{BECH}$ at that time. We were unable to stratify our collar deployment on the basis of the relative density of caribou in specific areas across this range because information on fine-scale densities of caribou was unavailable. We did not collar bull caribou because of local concerns regarding the potential effects of radio collars on bulls when their necks expand during the rut. A board member from the local hunters and trappers' organization accompanied us during the capture operation. In March 2001, while the BECH was wintering near Deline, Northwest Territories, we deployed seven more VHF radio collars on female caribou in anticipation of conducting another photo census in July 2001.

\section{Pre-Survey Monitoring of Caribou Distribution}

We conducted VHF telemetry flights on 18 November 1999 and 29-30 April 2000 using an Aviat Husky with a 


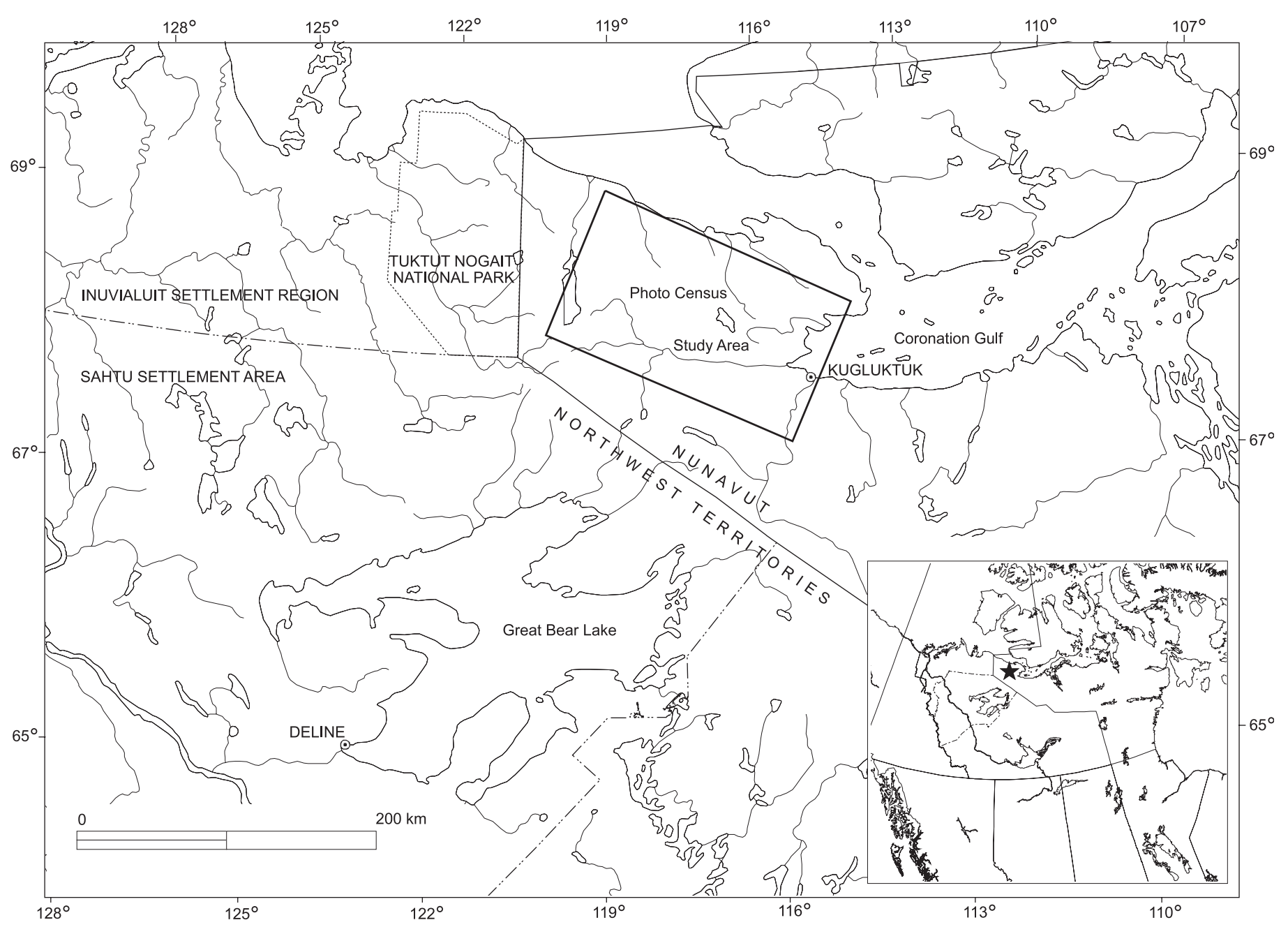

FIG. 1. Location of the study area used to estimate the size of the Bluenose-East caribou herd in June-July 2000.

pair of strut-mounted antennae. The purpose of these flights was to assess the late autumn and winter distributions of the collared caribou and to check for mortalities. The distribution of the BECH was also monitored by following the movements of two Bluenose-East caribou equipped with Argos satellite collars and active VHF beacons (Gunn and Dragon, 2000). These two caribou were frequently located amongst our VHF-equipped caribou during the 2000 census.

We began aerial monitoring of the radio-collared caribou to detect aggregations on 28 June 2000. Each morning from 28 June to 9 July, unless conditions were particularly cool or windy, we flew west from Kugluktuk in a Cessna 206 and began locating the radio-collared caribou. We visually confirmed the location of all collared caribou and determined whether they, and all other caribou within sight of their locations, were in well-defined aggregations or were loosely scattered on the landscape. We considered all caribou visible from the location of each collared caribou to be a single aggregation. If the first three collared caribou we located were not in aggregations suitable for photography (i.e., if the animals were too scattered for us to capture the entire group accurately in a series of photo- graphs), we concluded that our survey could not be conducted on that day and returned to Kugluktuk without locating more collared caribou. If some but not all caribou near the first three collars located were sufficiently aggregated for us to conduct our survey, we continued to locate other collared caribou, planning to return to these first three groups later in the day and photograph them if they had become sufficiently aggregated.

\section{Aerial Photography and Image Processing}

When we located an aggregation sufficient for photography, we circled the group at an altitude of $150-300 \mathrm{~m}$ above ground level (AGL), and a photographer in the back seat of the plane vertically photographed each aggregation with a handheld, motor-driven $35 \mathrm{~mm}$ Pentax mz-50 camera and a Pentax 28-80 $\mathrm{mm}$ zoom lens. We used two identical cameras, and another crew member reloaded film as needed, so the photographer was never out of film. We attempted to photograph each aggregation in a single pass to minimize movements between frames and to overlap successive frames by $\sim 20 \%$. We assigned a number to each aggregation and recorded its location, frequency of any 


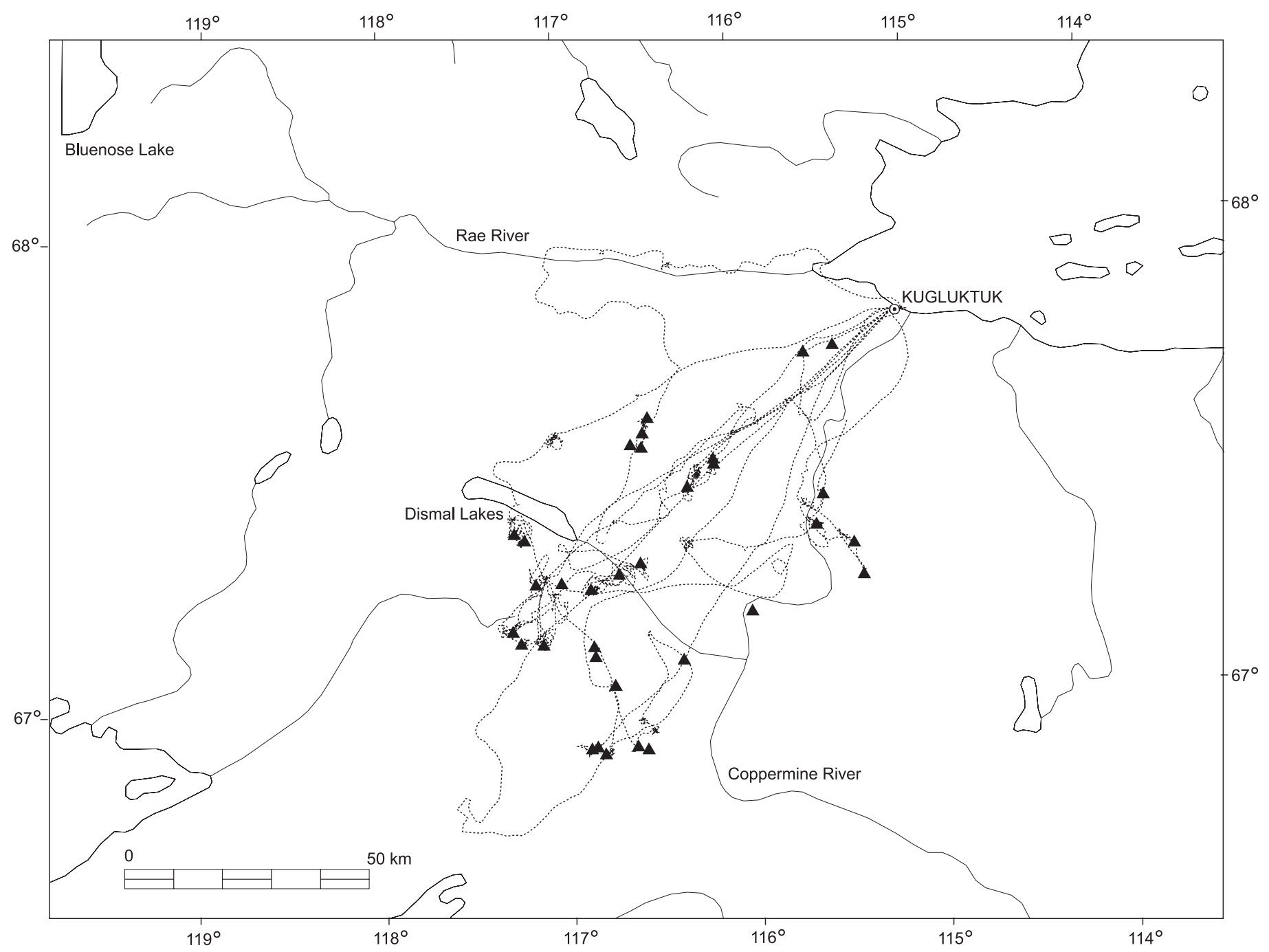

FIG. 2. Flight lines used during aerial reconnaissance to define the distribution of Bluenose-East caribou in September 1999. Triangles show locations where caribou were captured and radio-collared.

collars present, and the roll and frame numbers of any photographs taken. All groups were photographed using Kodachrome 200 ASA color transparency film. Slides were then scanned at 2400 dots per inch (dpi) using a Hewlett Packard Photosmart S20 slide scanner. We then imported the digital images comprising each group into the software program Corel Photopaint 9 (Corel Corporation, Ottawa, Ontario) and cropped off areas of overlap on adjacent frames to prevent double counting of individual caribou. Because we were able to enlarge the images enough to delineate precisely the position of each caribou relative to the neighboring caribou and terrain, we believe that very few caribou were omitted or counted twice in successive frames. Each frame was then arbitrarily georeferenced using the program Geotiff Examine 1.01 (Mentor Software Inc., Golden, Colorado), and all frames from each aggregation of caribou were imported as adjacent raster images into SPANS Explorer 7.1 (PCI Geomatics, Richmond Hill, Ontario) as a single raster layer for each aggregation. We then created a new point layer on top of the "geo-referenced" photographs and counted caribou by adding a new point over each caribou and then tallying the number of records in the layer. Three observers verified the number of caribou in each image, using a single point data layer for each group (i.e., consensus approach).

\section{Population Estimate}

Our count of calf and non-calf caribou provided a minimum estimate of the size of the BECH. However, because not all collared caribou are associated with aggregations and not all aggregations always contain a collared caribou, total herd size will always be larger than the minimum count obtained during a photo census (Russell et al., 1996). We estimated the total population size using two published methods. The first was presented by Russell et al. (1996) and is based on the Lincoln-Petersen Index as applied to radio-telemetry data by White and Garrott (1990). By this method, 


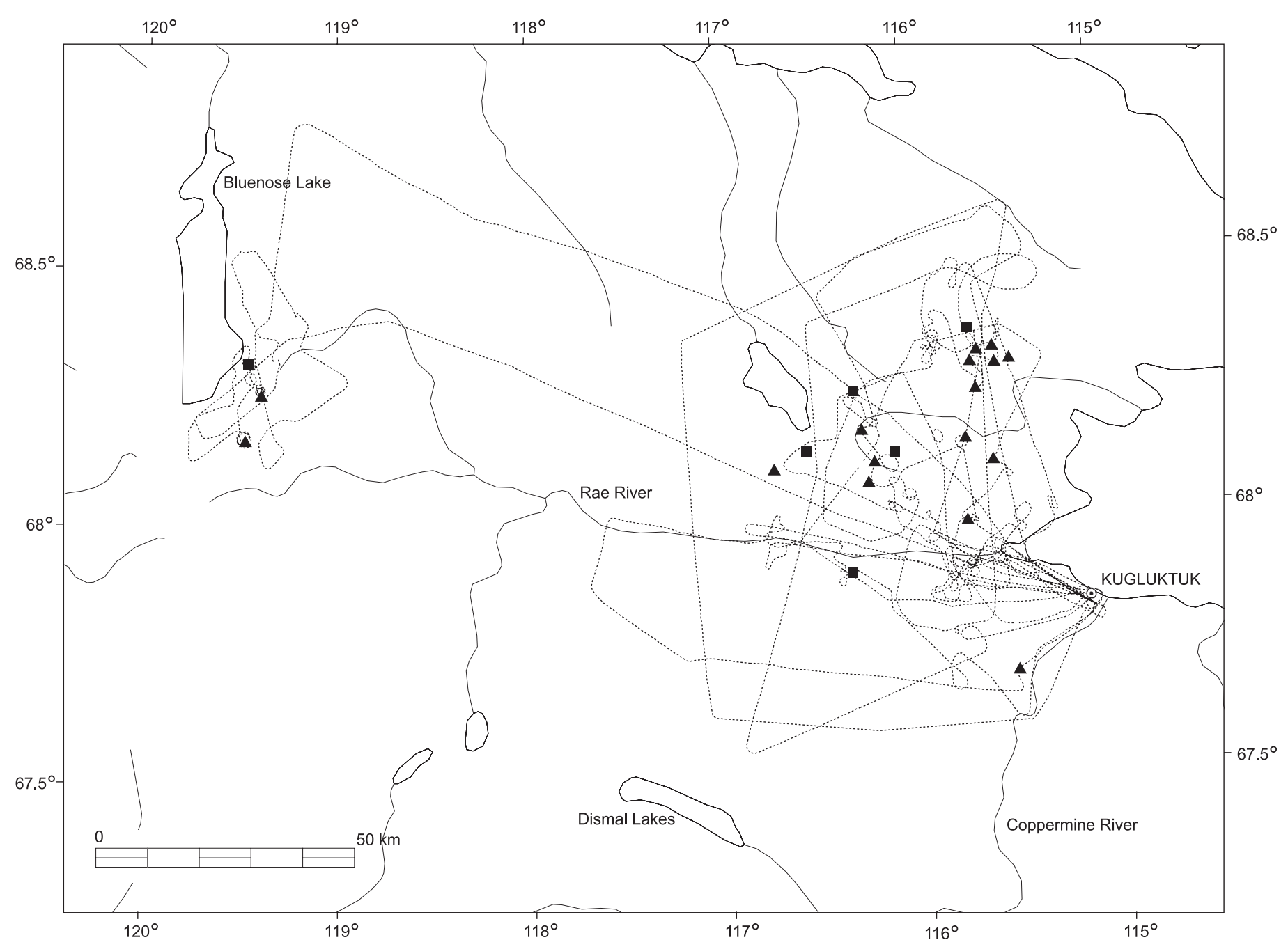

FIG. 3. Aerial reconnaissance flight lines used and locations of groups photographed during a post-calving photo census of the Bluenose-East caribou herd from 30 June to 6 July 2000. Triangles represent groups with at least one radio-collared caribou; squares represent groups with none.

$$
\mathrm{N}=(((\mathrm{M}+1) \cdot(\mathrm{C}+1)) /(\mathrm{R}+1))-1
$$

where $\mathrm{N}$ is the estimate of population size during the census, $\mathrm{M}$ is the number of radio-collared caribou present in the herd (including all collars known to be active during the survey), $\mathrm{C}$ is the number of caribou observed in aggregations containing at least one radio-collared caribou during the survey, and $\mathrm{R}$ is the number of radiocollared caribou observed in these aggregations during the survey.

The $95 \% \mathrm{CI}$ for the estimate can then be calculated as $\mathrm{N}_{\mathrm{i}}=1.96 \operatorname{Var}(\mathrm{N})^{\wedge} 0.5$, where:

$$
\operatorname{Var}(\mathrm{N})=\frac{(\mathrm{M}+1)(\mathrm{C}+1)(\mathrm{M}-\mathrm{R})(\mathrm{C}-\mathrm{R})}{(\mathrm{R}+1)^{2}(\mathrm{R}+2)}
$$

Rivest et al. (1998) showed that the Lincoln-Peterson estimator is negatively biased because the number of radio-collared caribou is higher in large groups than in smaller ones. Further, they argued that the heterogeneous spatial distribution and large and variable size of postcalving aggregations make the use of standard markrecapture methods inappropriate for estimating caribou abundance. As an alternative, they proposed using stochastic likelihood models to estimate abundance from post-calving photography counts (Rivest et al., 1998). Like the Lincoln-Petersen Index, the method proposed by Rivest et al. (1998) assumes that radio-collared caribou are randomly distributed throughout the population. Specifically, the proportion of radio-collared caribou in each herd should mirror the proportion of the total Bluenose population represented by that herd (i.e., $X_{i}=n N_{i} / T$, where $X_{i}$ is the number of radio collars in herd $i, n$ is the total number of collars, $N_{i}$ is the size of herd $i$ with $X_{i}$ radio collars, and $T$ is total population size). Each parameter in this formula is known except total population size, so total population size is varied until the best fit is found (i.e., the negative log-likelihood is minimized). Encountered aggregations without radio-collared individuals are excluded from the estimator, as these aggregations are generally less likely to 
be detected. Therefore, the data are fit to a truncated Poisson distribution, using likelihoods provided in Rivest et al. (1998).

In addition to employing the Lincoln-Peterson estimator, we also estimated total population size using the likelihoods in Rivest et al. (1998). We assumed a homogeneous detection probability because, as suggested by Rivest et al. (1998), groups that contained radio-collared animals but were not detected during our survey were likely missed because of the location of the collared animals, and not because of hardware failure. Confidence limits of this estimate were calculated using the likelihood profile (Hudson, 1971; White and Garrott, 1990: 262) calculated using program R, v 1.4.1 (Ihaka and Gentleman, 1996).

\section{RESULTS}

\section{Monitoring Caribou Distribution Prior to Photographic Surveys}

In November 1999, we accounted for 26 of the 34 collared caribou, including one mortality. In late April 2000, we located 19 of the remaining 33 caribou as they traveled north across Great Bear Lake. During this survey we detected a mortality near the Sahtu community of Deline, in an area where many caribou had spent the winter (Fig. 1). A second caribou, collared south of Kugluktuk in September 1999 (Fig. 2), was never located during our monitoring flights and was shot in early September 2001 near Horton Lake, $290 \mathrm{~km}$ west of its capture location. Horton Lake is well inside the range of the Bluenose-West caribou herd, and the radio collar this animal was wearing was functioning properly at the time it was killed. We concluded that this caribou was outside of our study area (i.e., with the Bluenose-West herd) during our survey, and we removed it from our pool of radio-collared caribou. In addition, we included in our sample the two Bluenose-East caribou mentioned previously that were equipped with Argos satellite collars and active VHF beacons. Thus, a maximum of 33 caribou with potentially active radio collars remained at the start of the 2000 census. During the census we accounted for 30 of these collared caribou.

\section{Post-Calving Survey in 2000}

We began aerial monitoring of the radio-collared caribou to detect aggregations on 28 June 2000. On 30 June, we photographed a tight aggregation of $\sim 1800$ caribou lying on packed snow and ice along the bank of the Coppermine River (Fig. 3), but most other caribou were in loose aggregations in the Rae-Richardson River areas west of Kugluktuk. The afternoon of 2 July was hot (high of $23^{\circ} \mathrm{C}$ ) with little wind. Although many caribou were loosely aggregated in the morning, most were tightly aggregated by mid-afternoon. On that day we photographed 15 groups containing 17 collared caribou and a minimum of 63133

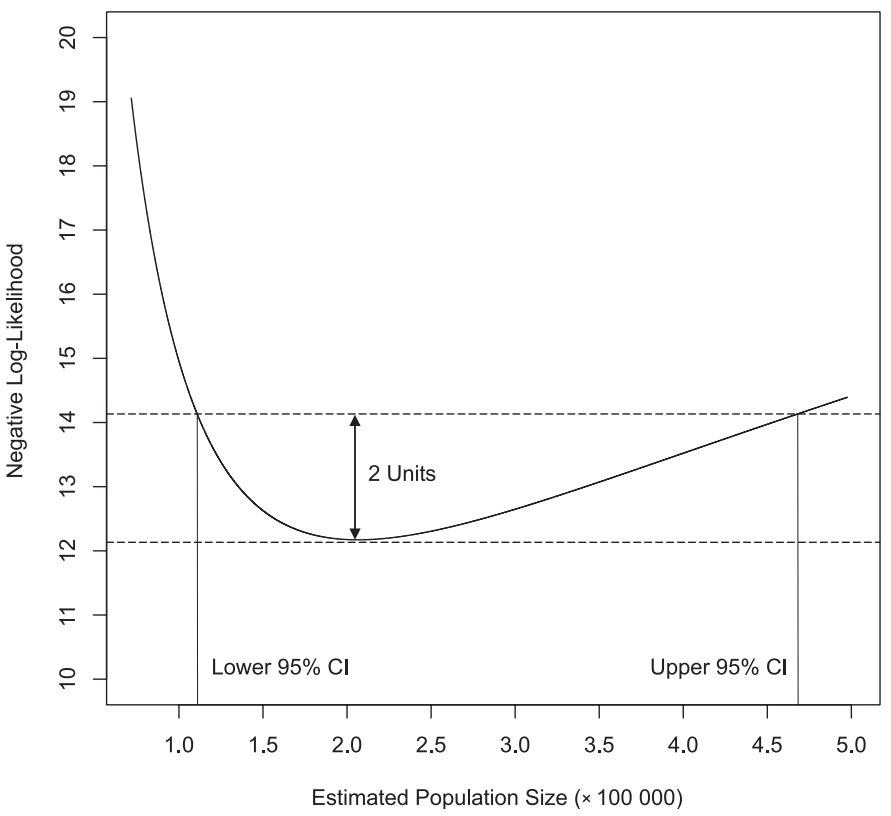

FIG. 4. Construction of the $95 \%$ confidence interval (CI) for the population estimate of the Bluenose-East caribou herd, calculated after Rivest et al. (1998). Estimation of the confidence interval based on the likelihood profile is after Hudson (1971). The asymmetric distribution of the likelihood profile indicates good confidence in the lower limits of the population estimate but poor confidence in the upper limit.

adult and 3214 calf caribou before the temperature dropped and the aggregations dissolved shortly after 22:30. Conditions were cool and windy on 3 and 5 July 2000, but we photographed four more distinct groups on 4 July and an additional seven groups on 6 July.

Groups photographed on 6 July near Bluenose Lake (Fig. 3), the proposed boundary between the BluenoseEast and Bluenose-West caribou herds (Nagy et al., 1999; unpubl. data), included three radio-collared BluenoseEast caribou (collared south of Kugluktuk just before the rut in 1999; Fig. 1) and five radio-collared Bluenose-West caribou (collared near Tuktoyaktuk in winter 2000, over $500 \mathrm{~km}$ northwest of where most of the Bluenose-East caribou wintered). Of the 135 calves and 18748 non-calf caribou photographed in the Bluenose Lake area on 6 July, we assume that $\sim 38 \%$ were Bluenose-East and $62 \%$ were Bluenose-West animals (corresponding to the ratio of collared Bluenose-East and Bluenose-West caribou found among those photographed in this area). To test the sensitivity of our population estimates to this assumed ratio, we varied the proportion of caribou assumed to belong to the $\mathrm{BECH}$ from $25 \%$ to $75 \%$ of all caribou counted in this area on 6 July. This variation resulted in changes of less than $10 \%$ to the total population estimates.

Conditions were cool from 7 to 9 July, and many of the collared caribou scattered and started moving south towards the Dismal Lakes (Fig. 1). On 9 July, we terminated the survey.

Overall, we accounted for 30 of the 33 potentially active radio collars and photographed 22 distinct groups containing 23 of these collars during the 2000 census (Table 1). 


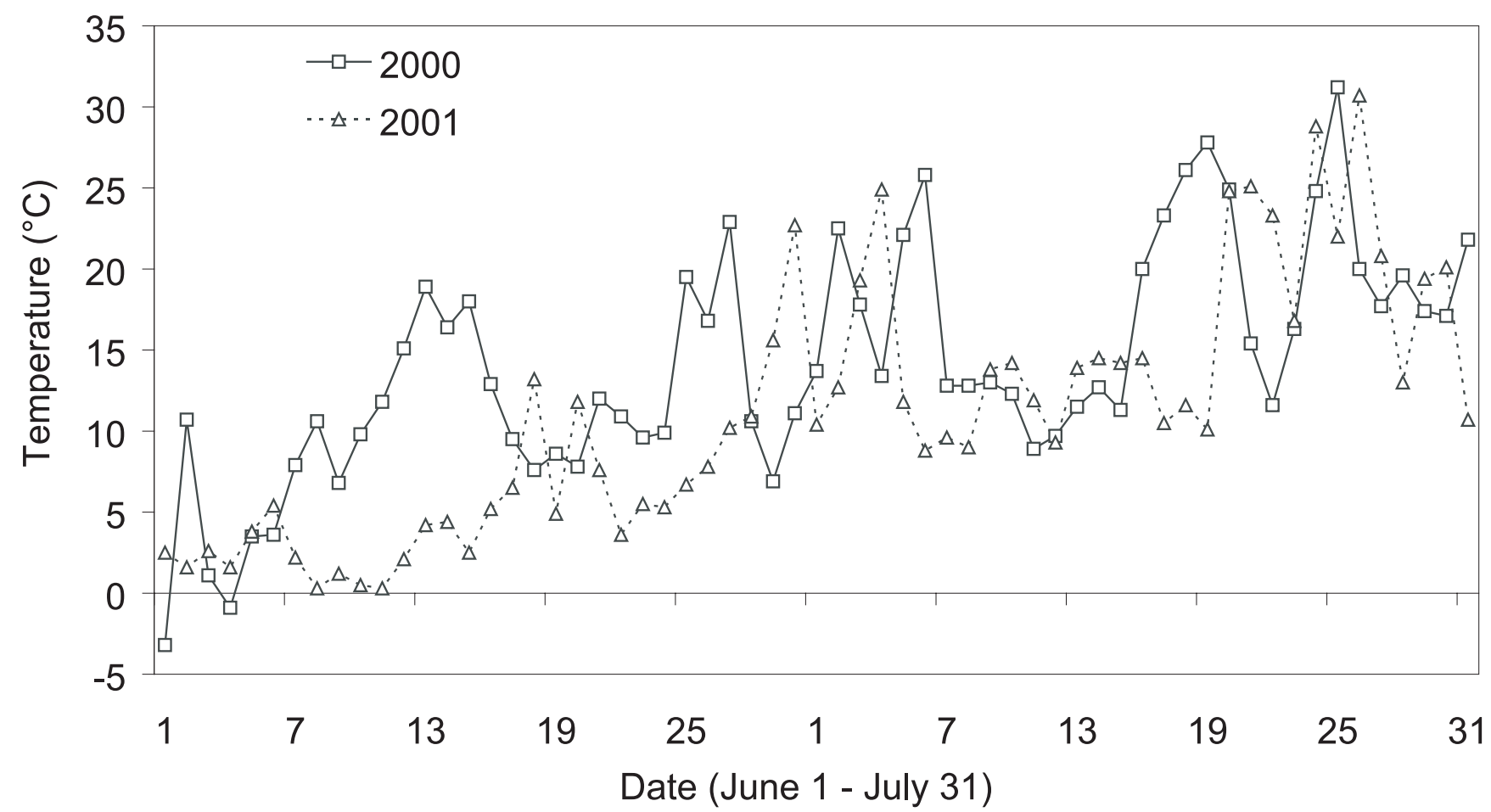

FIG. 5. Maximum daily temperatures measured at Kugluktuk, Nunavut, in June and July of 2000 and 2001. The higher temperatures in late June and early July 2000 may have increased insect harassment in that year, encouraging caribou aggregation.

Excluding caribou assumed to belong to the BluenoseWest herd (see above), we photographed a minimum of 84412 adult and 4193 calf caribou. However, only 16 of these groups (totaling 73393 non-calf caribou) contained at least one radio-collared caribou and thus could be included in the estimates of total population size. Using the Lincoln-Peterson estimator, this resulted in an estimate of 104000 (95\% CI of 84412-126100) non-calf caribou in the BECH. The stochastic model of Rivest et al. (1998) produced a considerably higher and more variable estimate of 208700 , with a 95\% CI of 118300-547000. Note that the confidence limits of the Rivest et al. estimate are nonsymmetric because the shape of the likelihood function is constrained on the lower end by the known minimum number of caribou in the herd (Fig. 4). This likelihood function indicates poor precision in the upper bound.

\section{DISCUSSION}

\section{General Applicability of Post-Calving Photography to Estimates of Caribou Herd Size}

Estimates of population size of Bluenose caribou have been attempted since the $1950 \mathrm{~s}$, but systematic aerial surveys began only in the 1970s (McLean and Russell, 1992). Early visual surveys often resulted in large standard errors and faced large potential observer bias (Latour et al., 1986). Calving-ground photo surveys, although an improvement, also often produce highly variable results
(Crête et al., 1986; Sutherland and Gunn, 1996; Gunn and Sutherland, 1997; Gunn et al., 1997). Although the technique is not reliable for all herds during all years, postcalving photography is the method of choice for surveying the Porcupine and other Alaskan herds, as well as the George River herd in Quebec and Labrador (Russell et al., 1996). Our method of digitally counting caribou provides a significant improvement over previous methods in that it requires no manual tallying of caribou numbers, and it is much easier for several people to verify a single count of each group (three observers verified our counts). Previous studies in which caribou were counted manually from slides projected on paper indicate that less experienced observers tend to undercount the number of caribou in most groups (McLean and Russell, 1992; Russell et al., 1996).

Caribou form aggregations in response to insect harassment, and insect harassment generally increases with temperature and decreases with wind (Downes et al., 1986; Mörschel and Klein, 1997; Colman et al., 2001). Although successful photo censuses were conducted on Bluenose caribou (East and West herds) in 1986, 1987, 1992, and 2000 , the lack of aggregations precluded completion of photo censuses in 1991 and 2001. We examined June and July weather data for Kugluktuk from 2000 and 2001. In late June and early July, daily maximum temperatures were generally higher (and wind speeds lower) in 2000 than in 2001 (Figs. 5 and 6). Presumably these conditions resulted in increased insect harassment during 2000.

Often, the cost of actually locating and photographing the aggregations during a photo census will be small relative to the cost of deploying and monitoring the radio 


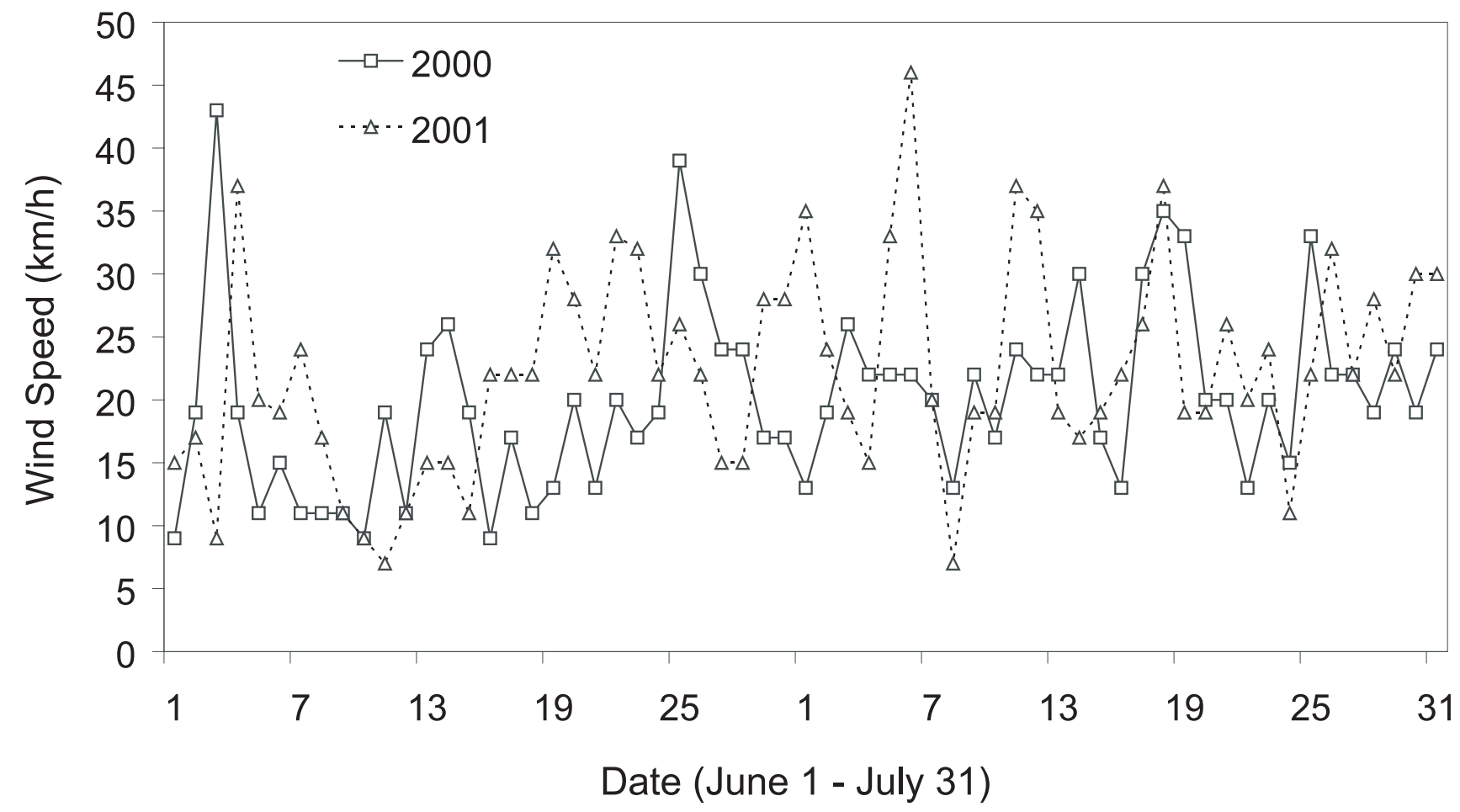

FIG. 6. Maximum daily wind speeds measured at Kugluktuk, Nunavut, in June and July of 2000 and 2001. The lower wind speeds in late June and early July 2000 may have increased insect harassment in that year, encouraging caribou aggregation.

collars. Thus, despite the variable and unpredictable nature of weather from one year to the next, we suggest that if radio collars are deployed in large numbers in March or April, conditions should be sufficient to complete the photo census within the life expectancy of most radio collars (i.e., 3 years). Costs incurred during a year when the census must be cancelled include some fixed-wing aircraft time to monitor for aggregations during days when weather suggests that caribou may be aggregating, daily minimums for the fixed-wing charter while waiting for weather conditions to improve, and travel and lodging costs for the survey crew.

\section{Estimating Total Herd Size Using Post-Calving Photography}

Although our minimum count alone alleviates most concerns regarding potential over-harvest of BluenoseEast caribou, actual estimates of population size are desirable for estimating total allowable harvest and for inferring population trends. We employed two methods to estimate total herd size, and they provided considerably different estimates. Russell et al. (1996) discussed four assumptions upon which an accurate estimate of population size using post-calving photography and the Lincoln-Peterson estimator is dependent. Assumptions one, three, and four also apply to the Rivest et al. (1998) estimator. The degree to which each assumption was met during our census is discussed below.

Assumption 1: The population is closed. Although distribution and genetic evidence suggest that Bluenose-
East caribou are distinct from adjacent caribou populations, our study provides some evidence of range overlap during post-calving with the adjacent Bluenose-West caribou herd. Also in evidence is the female caribou we collared south of Kugluktuk in September 1999 (Fig. 2) that was shot in early September 2001 while well inside the range of the Bluenose-West caribou herd. Although we documented some seasonal range overlap between BluenoseEast and West caribou, it is important to note that range overlap during winter is common among different herds of barren-ground caribou (Gunn and Dragon, 2000). Distinct caribou herds have traditionally been identified by their fidelity to calving grounds (Gunn and Miller, 1986). However, it is spatial separation during breeding that will result in genetic distinctiveness. Although we documented some evidence of mixing amongst the Bluenose-East and West herds, it was relatively uncommon, and there is little evidence that any mixing occurred during the rut (J.A. Nagy et al., unpubl. data). Both genetic evidence and spatial distribution suggest that our population was largely closed, particularly during the short time interval in which the survey was conducted.

Assumption 2: All highly aggregated groups contain at least one radio-collared caribou and thus can be located. In contrast to the Lincoln Peterson estimator, the stochastic estimator discussed by Rivest et al. (1998) is not bound by this assumption. Nonetheless, when environmental conditions are suitable, most herds of migratory caribou tend to aggregate in large groups during the post-calving period (Whitten, 1985; Valkenburg et al., 1985; Russell, 1990; McLean and Russell, 1992; Russell et al., 1996). When we deployed radio 
collars in anticipation of conducting this survey, we were unaware of the large size of the herd and believed we were deploying collars at a rate of one or more collars per 1000 caribou in the herd. However, during the census we found that we actually had only one collar per 3500 or more caribou, and we did photograph several large aggregations in which we located no collared animals (Table 1). Although this was potentially problematic, aggregations were clustered nonrandomly throughout the landscape (Fig. 3; see also McLean and Russell, 1992), and all aggregations we observed without active collars were located near other aggregations that were located via telemetry. Observations indicate that three of the seven caribou located during the survey but not included in photographed aggregations tended to be in small, scattered groups of caribou. Although the other four were not directly observed, their radio signals were heard within our study area on several occasions, and we believe that during our extensive travels we would have observed any large aggregations that included them. Given the clustered distribution of aggregations and the fact that we detected no aggregations of caribou outside this distribution despite extensive travels throughout the study area (Fig. 3), we believe that we missed few, if any, large aggregations because of insufficient distribution of collars. However, because we did not collar bull caribou, we acknowledge that we may have missed some aggregations if bulls were sexually and spatially segregated during the census. Although we could not determine the sex of all caribou in all photographs, many bulls were conspicuous in several photos included in our estimate. Further, Russell et al. (1996) reported that mixing of the sexes occurred in large aggregations formed by the George River caribou herd during the post-calving photo census they conducted in 1993. Although we did not strictly meet the conditions for this assumption, we believe this violation had little influence on our estimate generated by the Lincoln Peterson estimator.

Assumption 3: Radio-collared animals are randomly distributed throughout the herd. We used a fixed-wing aircraft and satellite telemetry data (J.A. Nagy et al., unpubl. data) to define the distribution of Bluenose-East caribou in September 1999. We then attempted to distribute the radio collars evenly across this distribution. Further, random mixing of collared caribou likely occurred between September 1999 and the time of our survey in late June 2000 (e.g., Valkenburg et al., 1985; Russell et al., 1996). Another indication that this assumption was met is that the probability that an aggregation would contain one or more radiocollared caribou increased with group size (Fig. 7).

Assumption 4: No significant movements of individual caribou among photographed groups used in the estimate occur during the census. Although the aggregations we photographed during the census tended to be clustered (Fig. 3), we did not detect any instances in which collared animals left one aggregation and were subsequently located in another during the seven days of the census. Further, most of the photographed caribou included in our estimate were photographed in a single day (2 July 2000).
TABLE 1. Calf and non-calf caribou counted in photographs taken west of Kugluktuk, Nunavut from 30 June to 6 July 2000. Since we could not reliably discern calves in many of the photos, our estimate of calves is an extreme minimum.

\begin{tabular}{|c|c|c|c|c|c|}
\hline \multirow[b]{2}{*}{ Date } & \multirow[b]{2}{*}{ Group } & \multirow[b]{2}{*}{ No. of radio collars } & \multicolumn{2}{|c|}{ No. counted ${ }^{1}$} & \multirow{2}{*}{$\frac{\text { Percent }}{\text { Calf }}$} \\
\hline & & & Non-Calf & Calf & \\
\hline 30 June & 1 & 1 & 2023 & & \\
\hline 1 July & 2 & 0 & 1386 & 160 & 11.5 \\
\hline 2 July & 3 & 1 & 1787 & & \\
\hline 2 July & 4 & 0 & 452 & 19 & 4.2 \\
\hline 2 July & 5 & 2 & 16727 & 761 & 4.5 \\
\hline 2 July & 6 & 1 & 11389 & & \\
\hline 2 July & 7 & 0 & 682 & 79 & 11.6 \\
\hline 2 July & 8 & 3 & 4975 & 261 & 5.2 \\
\hline 2 July & 9 & 3 & 7109 & 741 & 10.4 \\
\hline 2 July & 10 & 2 & 5468 & 642 & 11.7 \\
\hline 2 July & 11 & 1 & 1745 & & \\
\hline 2 July & 12 & 0 & 3249 & 152 & 4.7 \\
\hline 2 July & 13 & 1 & 3558 & 224 & 6.3 \\
\hline 2 July & 14 & 1 & 3148 & 335 & 10.6 \\
\hline 2 July & 15 & 1 & 2844 & & \\
\hline 4 July & 16 & 0 & 2904 & 168 & 5.8 \\
\hline 4 July & 17 & 2 & 3424 & 385 & 11.2 \\
\hline 6 July & 18 & $0^{2}$ & 1925 & & \\
\hline 6 July & 19 & 1 & 2493 & 215 & 8.6 \\
\hline 6 July & 20 & 1 & $1953^{1}$ & & \\
\hline 6 July & 21 & $1^{2}$ & $11334^{1}$ & & \\
\hline 6 July & 22 & $1^{2}$ & $5461^{1}$ & 135 & 2.5 \\
\hline Total & & 23 & $96036^{1}$ & 4277 & 8.6 \\
\hline
\end{tabular}

${ }^{1}$ Of the 135 calves and 18748 non-calf caribou photographed in the Bluenose Lake area on 6 July 2000, we assume that $\sim 38 \%$ were Bluenose-East and $62 \%$ were Bluenose-West animals. We base this assumption on the presence of three collared BluenoseEast (2 VHF and $1 \mathrm{UHF}$ ) and five collared Bluenose-West (VHF) animals amongst all the caribou counted in this area (Groups 20-22). Thus, subtracting the assumed Bluenose-West animals, the minimum total numbers of Bluenose-East caribou photographed are 84412 adults and 4193 calves.

${ }^{2}$ These groups also contained at least one collared BluenoseWest caribou (J.A. Nagy, unpubl. data).

The second largest contribution to our estimate came from caribou photographed four days later in an area $130 \mathrm{~km}$ from the most westerly group photographed on 2 July (Fig. 3). Nonetheless, groups of unmarked caribou could have moved from one aggregation to another. If this was common or involved large numbers of caribou, then some collared caribou should have been involved in this shortterm mixing.

Another potential source of bias with both methods is in the estimation of the number of living caribou with functional radio collars. We assumed that 33 Bluenose-East caribou had functioning collars during our census and were thus available to be found. However, three of these caribou were never located after collaring, and we are uncertain whether they were present in our study area with functioning collars during the census. Assuming that they were unavailable for location during the census results in only minor reductions in both estimates of abundance, with little gain in precision: for the Peterson estimator, the 


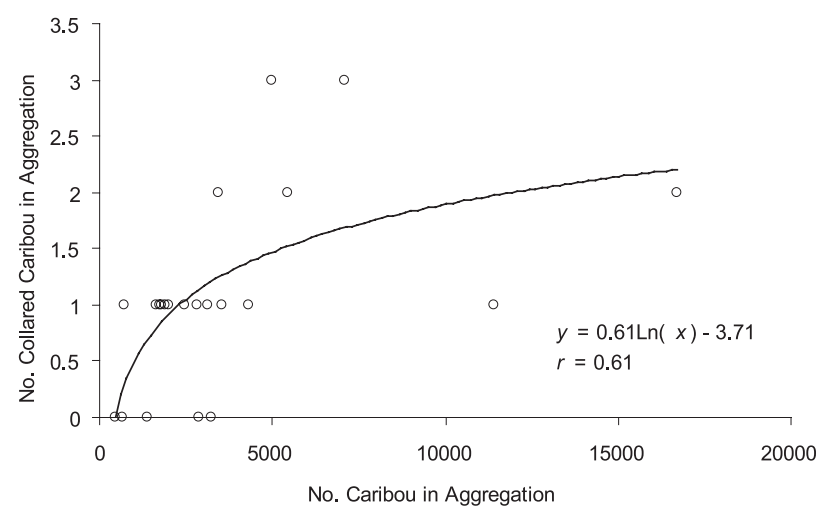

FIG. 7. The number of radio-collared caribou contained in each aggregation $(n=22)$ in relation to the size of the aggregation. Note that the largest aggregation not containing a radio-collared caribou contained 3249 individuals, and the smallest aggregation found containing a radio-collared caribou numbered 742 individuals.

result is 94800 (95\% CI $85800-103800)$ ) for the Rivest et al. estimator, 206240 (95\% CI 107600-497000). Thus, our inability to enumerate precisely the number of caribou with functioning radio collars in our study area during the census resulted in little bias in our estimates.

Perhaps an even more important issue, but one not explicitly discussed by Russell et al. (1996), is the heterogeneity of detection probabilities of caribou aggregations. White and Garrott (1990) originally discussed using the Lincoln Peterson estimator to estimate the abundance of a dispersed wildlife population in which a sample of members had been marked. They explicitly stated that to avoid a heterogeneous detection probability, the marks must not influence the probability of detecting an individual during the survey. As employed by Russell et al. (1996), the Lincoln Peterson estimator assumes that all aggregations contain at least one radio-collared caribou, and these collars are essential for detection of the aggregations. Although some groups without collars will typically be detected during a survey, on average the probability of detecting these groups must be somewhat lower than it is for groups containing active collars. Inclusion of aggregations without collars results in a heterogeneous detection probability among groups included in the estimate, and thus a negative bias in the estimate (White and Garrott, 1990). To mitigate this bias, Russell et al. (1996) included only groups containing at least one active collar in their estimate. Ignoring groups without collars should also bias the estimate low. However, Russell et al. (1996) assumed that all caribou present in small groups without collars were photographed and counted later as members of other groups with collars. During our census, we photographed 11019 caribou in seven groups without radio collars, and the timing and location of these sightings make it unlikely that most of these caribou could have been included in counts of groups containing collared members (see discussion of assumption 4 above).

Russell et al. (1996) used post-calving photography and the Lincoln Peterson estimator to estimate the size of the
George River herd in Quebec and Labrador in July 1993. Rivest et al. (1998) demonstrated that during this photo census, the probability that a group of 5000 would contain at least one radio collar was only 0.52 . (For groups of 20000 or more animals, the probability was 0.95 or higher.) Because of these low inclusion probabilities, Rivest et al. (1998) concluded that the Lincoln Peterson estimator was biased low and suggested the use of their stochastic likelihood estimator. We concur with Rivest et al. (1998) that their estimator will generally be superior to the Lincoln Peterson estimator for estimating total herd size with post-calving photography, particularly for large herds. However, the smaller size and clustered post-calving distribution of the BECH relative to the George River herd, as well as the fact that not all caribou were associated with large aggregations during our census, suggests that the Lincoln Peterson estimator may have produced a less biased estimate in our case.

Rivest et al. (1998) suggested that the heterogeneous distribution of post-calving aggregations favored the use of their estimator. In our case, we believe that this heterogeneous distribution actually reduced the likelihood that we missed any large aggregations during our census. Specifically, although we did photograph several groups that did not contain radio-collared caribou, they were generally close to groups containing collared individuals (Fig. 3). Thus, the presence of radio-collared caribou facilitated location of most, if not all, of the aggregations we photographed. Given this, and because our study area was systematically searched for aggregations with or without radio-collared individuals (Fig. 3), we suggest that neither the heterogeneous distribution of aggregations nor the presence of aggregations without collared individuals appreciably biased our population estimate based on the Lincoln-Peterson estimator. Moreover, we have little confidence that the discrepancy between our minimum count (84412 including all 23 aggregations listed in Table 1) and the mean estimate generated using the Rivest method (208700) is realistic. Although we could include only 16 aggregations containing 23 collars in both population estimators, we accounted for 30 of the 33 collars during the survey. Unless the three collared caribou unaccounted for during our survey were associated with more than 100000 caribou, the mean estimate generated by the Rivest et al. (1998) estimator seems biologically implausible. This is not an inherent fault of the estimator but rather a result of the fact that not all caribou during our survey were associated with large aggregations. Considering the uncertainty involved in meeting all of the assumptions of either estimator, we encourage the use of the minimum count afforded by post-calving photography where it applies to management.

\section{MANAGEMENT IMPLICATIONS}

The historic distribution of the Bluenose caribou herd (all herds combined) encompasses four land-claim areas. Recent confirmation of three genetically distinct herds of Bluenose caribou within this distribution will facilitate the 
co-management of Bluenose caribou by enabling regional land-claim organizations and the respective territorial governments to focus on only the herd(s) harvested by peoples within their respective areas. The results of this study are needed to determine sustainable harvest levels for the Bluenose-East population.

Presently, harvest information is being collected in two of three land-claim areas within the distribution of the BECH. In the Sahtu Settlement Area, harvest data are collected through monthly interviews of Sahtu beneficiaries (Janet Bayha, pers. comm. 2003). Non-beneficiaries and non-aboriginals residing in the Sahtu Settlement Area are not interviewed. The Nunavut Harvest Study (Nunavut Wildlife Management Board, unpubl. data) collects similar data regarding the harvest of Bluenose caribou by Kugluktuk residents, but preliminary results are presently unavailable. Assuming a conservative harvest rate of 5\%, and using the minimum population estimates obtained in the present study, the total harvest from the BECH should not exceed 5000 caribou annually. Until better estimates of total harvest are obtained, it is not possible to determine whether present harvest levels are sustainable.

This study confirms a minimum population size that far exceeds the previous estimate of total herd size (Nagy et al., 1999) and even exceeds the estimate for all Bluenose caribou in the 1980s (McLean and Russell, 1992). Present densities of Bluenose-East caribou may represent at least a 25-year high (Latour et al., 1986; McLean and Russell, 1992; Nagy et al., 1999). Evidence suggests that, over the long term, a relationship between caribou population growth and forage abundance that is dependent on caribou density may lead to unstable or even cyclic fluctuations in caribou abundance (Messier et al., 1988; Ferguson and Messier, 2000; Solberg et al., 2001). Given the slow regeneration of vegetation in Arctic ecosystems, it may take decades for forage, and then caribou numbers, to recover following a decline induced by density-dependent overgrazing (Manseau et al., 1996; Crête and Doucet, 1998; Ferguson et al., 2001). We do not know the present position of the $\mathrm{BECH}$ relative to the carrying capacity of the herd's range. However, given that densities seem high relative to historic levels, future management of this herd should include regular monitoring of body condition. This recommendation is based on the premise that animals on the range are often the best indicators of the status of the range itself (e.g., Klein, 1968; Messier et al., 1988; Hjelford and Histol, 1999; Ferguson and Messier, 2000). Although it may be difficult to avoid a forage-induced population crash, politically it would be useful to be able to predict a population crash and determine what, if any, co-management actions should be undertaken.

\section{ACKNOWLEDGEMENTS}

Funding for this project was provided by the Nunavut Department of Sustainable Development and the Sahtu Renewable Resources
Board. We acknowledge the logistical support provided by Damian Panayi, Monica Angohiatok, Lawrence Benjamin, Allen Niptanatiak, and Gordon Taniton. Zonko Dancevic and Dale Simpson piloted the helicopters during caribou capture operations. Todd Svarckopf and Jim Philips piloted the fixed-wing plane during the 2000 and 2001 surveys, respectively. David Taylor suggested using SPANS to count the caribou in the digital images.

\section{REFERENCES}

BANFIELD, A.W.F. 1954. Preliminary investigation of the barrenground caribou. Canadian Wildlife Service Wildlife Management Bulletin Series 1, No. 10A.

COLMAN, J.E., PEDERSEN, C., HJERMANN, D.O., HOLAND, O., MOE, S.R., and REIMERS, E. 2001. Twenty-four-hour feeding and lying patterns of wild reindeer Rangifer tarandus tarandus in summer. Canadian Journal of Zoology 79:2168-2175.

COUTURIER, S., COURTOIS, R., CRÉPEAU, H., RIVEST, L.P., and LUTTICH, S. 1996. Calving photo-census of the Rivière George caribou herd and comparison with an independent census. Rangifer Special Issue 9:283-296.

CRÊTE, M., and DOUCET, G.J. 1998. Persistent suppression in dwarf birch after release from heavy summer browsing by caribou. Arctic and Alpine Research 30:126-132.

CRÊTE, M., RIVEST, H., JOLICOEUR, J.M., BRASSARD, J.M., and MESSIER, F. 1986. Predicting and correcting helicopter counts of moose with observations made from fixed-wing aircraft in southern Quebec. Journal of Animal Ecology 23:751-761.

DOWNES, C.M., THEBERGE, J.B., and SMITH, S.M. 1986. The influence of insects on the distribution, microhabitat choice, and behavior of the Burwash Caribou Herd. Canadian Journal of Zoology 64:622-629.

FERGUSON, M.A.D., and MESSIER, F. 2000. Mass emigration of Arctic tundra caribou from a traditional winter range: Population dynamics and physical condition. Journal of Wildlife Management 64:168-178.

FERGUSON, M.A.D., GAUTHIER, L., and MESSIER, F. 2001. Range shift and winter foraging ecology of a population of arctic tundra caribou. Canadian Journal of Zoology 79:746-758.

GUNN, A., and DRAGON, J. 2000. Seasonal movements of satellitecollared caribou from the Bathurst herd. 1999-2000 Annual Report to the West Kitikmeot Slave Study, Yellowknife NT. 27 p.

GUNN, A., and MILLER, F.L. 1986. Traditional behaviour and fidelity to caribou calving grounds by barren-ground caribou. Rangifer Special Issue 1:151-158.

GUNN, A., and SUTHERLAND, M. 1997. Surveys of the Beverly calving grounds, 1957-1994. File Report 120. Yellowknife: Department of Resources, Wildlife and Economic Development, Government of the Northwest Territories. $119 \mathrm{p}$.

GUNN, A., DRAGON, J., and NISHI, J. 1997. Bathurst Calving Ground Survey, 1996. File Report 119. Yellowknife: Department of Resources, Wildlife and Economic Development, Government of the Northwest Territories. $63 \mathrm{p}$.

HJELJORD, O., and HISTOL, T. 1999. Range-body mass interactions of a northern ungulate: A test of hypothesis. Oecologia 119:326-339. 
HUDSON, D.J. 1971. Interval estimation from the likelihood function. Journal of the Royal Statistical Society 33:256-262.

IHAKA, R., and GENTLEMAN, R. 1996. R: A language for data analysis and graphics. Journal of Computation and Graphical Statistics 5:299-314. (Program R is available free at URL: http://www.r-project.org)

JACOBSEN, R. 1979. Wildlife and wildlife habitat in the Great Slave and Great Bear Lake regions 1974-1979. Environmental Studies No. 10. Ottawa: Department of Indian Affairs and Northern Development. 134 p.

KLEIN, D.R. 1968. The introduction, increase, and crash of reindeer on St. Matthew Island. Journal of Wildlife Management 32: 350-367.

LATOUR, P., WILLIAMS, M., and HEARD, D. 1986. A calving ground and population estimate for the Bluenose caribou herd in 1983. File Report 61. Yellowknife: Department of Resources, Wildlife and Economic Development, Government of the Northwest Territories.

MANSEAU, M., HUOT, J., and CRÊTE, M. 1996. Effects of summer grazing by caribou on composition and productivity of vegetation: Community and landscape level. Journal of Animal Ecology 84:503-513.

McLEAN, B.D., and RUSSELL, H.J. 1992. Photocensus of the Bluenose caribou herd in July 1986 and 1987. File Report 108. Inuvik: Department of Renewable Resources, Government of the Northwest Territories. $33 \mathrm{p}$.

MESSIER, F., HUOT, J., LE HENAFF, D., and LUTTICH, S. 1988. Demography of the George River caribou herd: Evidence of population regulation by forage exploitation and range expansion. Arctic 41(4):279-287.

MÖRSCHEL, F.M., and KLEIN, D.R. 1997. Effects of weather and parasitic insects on behaviour and group dynamics of caribou of the Delta Herd, Alaska. Canadian Journal of Zoology 75: 1659-1670.

NAGY, J.A., BRANIGAN, M., VEITCH, A., POPKO, R., and NISHI, J. 1999. Draft co-management plan for the Bluenose caribou herd and work plans for years 1999/2000 to 2003/2004 Inuvik: Department of Resources, Wildlife and Economic Development, Government of the Northwest Territories. $41 \mathrm{p}$. RIVEST, L.P., COUTURIER, S., and CREPEAU, H. 1998. Statistical methods for estimating caribou abundance using postcalving aggregations detected by radio telemetry. Biometrics 54:865-876.

RUSSELL, H.J. 1990. A photocensus of the Kaminuriak Herd in July 1987. File Report No. 97. Yellowknife: Department of Renewable Resources, Government of the Northwest Territories.

RUSSELL, H.J., COUTURIER, S., SOPUCK, L.G., and OVASKA, K. 1996. Post-calving photo-census of the Rivière George caribou herd in July 1993. Rangifer Special Issue 9:319-330.

SOLBERG, E.J., JORDHOY, P., STRAND, O., AANES, R., LOISON, A., SAETHER, B.E., and LINNELL, J.D.C. 2001. Effects of density-dependence and climate on the dynamics of a Svalbard reindeer population. Ecography 24:441 - 451.

SUTHERLAND, M., and GUNN, A. 1996. Bathurst calving ground surveys, 1965 - 1996. File Report 118. Yellowknife: Department of Resources, Wildlife and Economic Development, Government of the Northwest Territories. $97 \mathrm{p}$.

THOMAS, D.C. 1969. Population estimates and distribution of barren-ground caribou in Mackenzie District, N.W.T., Saskatchewan, and Alberta-March to May, 1967. Canadian Wildlife Service Report Series No. 9. 44 p.

VALKENBURG, P., ANDERSON, D.A., DAVIS, J.L., and REED, D.J. 1985. Evaluation of aerial photocensus technique for caribou based on radio-telemetry. Proceedings of the Second North American Caribou Workshop. McGill Subarctic Research Paper 40:287-299.

WHITE, G.C., and GARROTT, R.A. 1990. Analysis of wildlife radio-tracking data. San Diego: Academic Press.

WHITTEN, K.R. 1985. Censusing the porcupine caribou herd: Practical application of aerial photo techniques. Proceedings of the Second North American Caribou Workshop. McGill Subarctic Research Paper 40:285-286. 